\title{
Breve relato sobre a vida e obra de Professora Fernanda Margarida Barbosa Coutinho
}

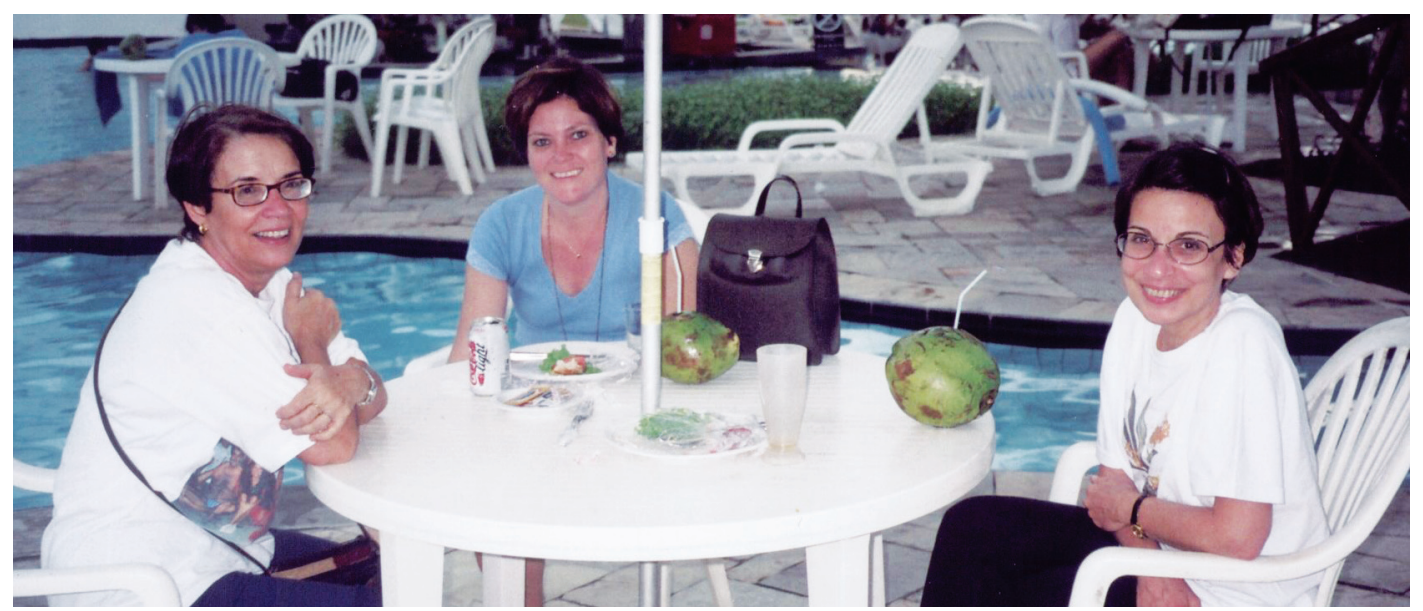

Falar sobre a professora e amiga Fernanda Coutinho é para mim uma mistura de sentimentos de tristeza, pela sua partida inesperada e precoce, orgulho e admiração, por ter tido o privilégio e a felicidade de conviver com ela tantos anos, período no qual eu e centenas de professores e pesquisadores tivemos a oportunidade de receber ensinamentos não apenas de Química Orgânica e Ciência de Polímeros como também de como exercer a atividade gratificante de Professor.

Meu convívio com Fernanda teve início durante o meu estágio de Iniciação Científica nos laboratórios do então Núcleo de Macromoléculas da Universidade Federal do Rio de Janeiro. Naquela época, em 1971, ela já era professora concursada do Instituto de Química da UFRJ, Mestre em Ciência pelo Programa de Química Orgânica do IQ/UFRJ, e lecionava Química Orgânica para várias turmas da Escola de Química, Instituto de Química e Faculdade de Farmácia da UFRJ.

A sua atuação como professora era única e peculiar. Os alunos que ingressaram no Programa de Pós-Graduação em Química Orgânica do Instituto de Química da UFRJ devem com certeza se lembrar do Curso de Nivelamento em Química Orgânica ministrado pela professora Fernanda. As aulas aconteciam durante os meses quentes de janeiro e fevereiro. Mesmo assim, o seu conhecimento, didática e empolgação contagiante pelo tema ministrado conseguiam prender a atenção de todos os alunos.

Fernanda foi também um dos mais importantes ícones da Pesquisa de Materiais Poliméricos no Brasil. O seu Currículo Lattes enumera mais de 200 publicações em periódicos indexados na área de Química Orgânica e Polímeros, 2 livros publicados, 4 capítulos de livro e inúmeras apresentações em Congresso. A produção científica deixada pela professora
Fernanda é reconhecida também internacionalmente, com mais de 1400 citações registradas no Web of Science e na base Scopus, o que corresponde a um Fator H de 20. Nesse sentido, a Folha de São Paulo publicou em 1999 a lista de pesquisadores brasileiros mais citados e Fernanda figurava entre eles.

A atuação da professora Fernanda na área de Polímeros não ficava restrita ao ensino de Graduação, Pós-Graduação e Pesquisa. Ela foi uma das principais responsáveis pela criação e consolidação do Programa de Pós-Graduação em Ciência e Tecnologia de Polímeros na UFRJ.

Após a sua aposentadoria pela UFRJ, ela ingressou na Universidade Estadual do Rio de Janeiro (UERJ) como Professora Visitante no Departamento de Processos Industriais, e trabalhou com a mesma competência na criação do Curso de Especialização em Polímeros desse Departamento. Em 2001, já como Professora Titular da UERJ ela participou ativamente do Projeto do Curso de Mestrado em Química, com áreas de concentração em Polímeros e Química Ambiental, sendo, após sua criação, Coordenadora do Programa. Ela estava fortemente envolvida no projeto de criação do Curso de Doutorado nessa mesma área, também na UERJ.

Essa intensa atividade acadêmica foi reconhecida pela comunidade científica brasileira: Fernanda era Bolsista de Produtividade em Pesquisa do CNPq - Nível 1A e recebeu Bolsa Cientista do nosso Estado pela FAPERJ de 2003 a 2009.

Apesar de toda essa atuação nos diversos setores da Academia, tanto na UFRJ como na UERJ, era quando exercia a função de orientadora que seu caráter, carisma e sabedoria mostravam-se em sua totalidade. Ela orientou 49 dissertações 
de Mestrado, 27 Teses de Doutorado, 12 monografias de final de curso e mais de 30 alunos de Iniciação Científica. Para todos esses alunos, Fernanda passava, com sua firmeza característica, todo o seu saber e coerência. Sempre estava pronta a ajudar, a dar conselhos, a participar.

Toda essa brilhante trajetória era compartilhada com uma dedicação única à família, assumindo todas as atividades que os cargos de mãe, esposa e filha exigem.

Por tudo isso, a Comunidade Brasileira de Química e de Polímeros perde uma importante pesquisadora, professora, orientadora.

Vários ex-alunos e colegas sentiram-se chocados com o seu falecimento. Transcrevo a seguir, o depoimento da professora Eloisa Biasotto Mano, sua professora e orientadora durante toda a carreira profissional, e alguns depoimentos de colegas e ex-alunos da inesquecível professora Fernanda Coutinho.

\section{Bluma Guenther Soares}

\section{Depoimento da professora Eloisa Biasotto Mano}

Fernanda Margarida Barbosa Coutinho - que se foi tão cedo, tão inesperadamente... Que saudade... Eu contava com sua especial atenção para rever alguns capítulos do livro que estou escrevendo, "A Natureza e os Polímeros", mas não foi possível; que pena...

Personalidade complexa, rica em qualidades, inteligente, espontânea, confiável, uma amiga, ex-aluna brilhante da qual eu muito me orgulhava.

Conheci Fernanda como estudante de minha disciplina Química Orgânica V - Polímeros, no Instituto de Química da Universidade Federal do Rio de Janeiro, em 1966. Garota morena, bonita, decidida, com personalidade marcante, estudiosa, inteligente, etc, etc...muitos adjetivos poderiam se listados para definir aquela menina que se destacava em meio a seus outros colegas de turma. Casouse com um colega, o Coutinho - tímido, calado, estável, apoio firme das horas incertas - bem apropriado para contrabalançar o vibrante temperamento de Fernanda... Lembro-me bem de seu casamento: poucas vezes vi noiva tão linda, com rosas brancas enfeitando seus cabelos, uma pintura inesquecível...

Tivemos um longo caminho paralelo. Primeiro, na condição de minha estudante de Graduação. Depois, como Monitora dessa disciplina; mais tarde, como Mestranda de Química Orgânica, realizando Tese sob minha orientação, defendida em 1971. Finalmente, como professora Adjunta do Instituto de Macromoléculas (IMA) da UFRJ, do qual eu era a Diretora, e aí permaneceu, com ativa atuação na Coordenação da Pós-Graduação do Instituto, durante muitos anos. Em 1998, aposentou-se no IMA e iniciou nova carreira acadêmica na Universidade Estadual do Rio de Janeiro, UERJ, com muito sucesso. Agora, infelizmente, na manhã do primeiro dia do ano, deixou para sempre o nosso convívio. Resta-nos muita saudade.
Nota do Professor Ariosvaldo Alves Barbosa Sobrinho Ex-aluno da professora Fernanda

Prezado Coutinho, filhas, familiares, amigos e colegas da comunidade acadêmica do IMA/UFRJ e UERJ,

Foi com muita tristeza que recebemos a noticia do falecimento prematuro da PROFESSORA FERNANDA COUTINHO, ORIENTADORA, AMIGA E EXCEPCIONAL FIGURA HUMANA.

Nós da comunidade acadêmica brasileira, ligados de alguma forma a Ciência e Tecnologia dos Polímeros, que tivemos o privilégio de conhecer de perto os cursos de pósgraduação do IMA/UFRJ, que convivemos com Fernanda Coutinho momentos de sabedoria e de crescimento interior, onde ela sempre com sua firmeza característica nos passava o seu saber com extrema convicção, infelizmente não a teremos mais em nosso convívio diário... Mas seu trabalho como pesquisadora será sempre lembrado por todos aqueles que almejarem algo neste domínio da ciência. Estejamos certos que na constelação das estrelas dos polímeros, ícones do conhecimento, existentes hoje tanto no IMA/UFRJ, como hoje também na UERJ, uma das mais brilhantes nos deixa, ficando um tremendo vazio em todos nós, que é o da professora Fernanda. Por outro lado, o que deve nos consolar é procurar entender que, se Deus assim o quis, foi porque certamente ela estará bem melhor ao seu lado, de alguma outra forma continuando a sua obra do crescimento e do engrandecimento humano, agora de outra forma.

Sentiremos muito a sua falta professora Fernanda...

\section{Nota da professora Elisabeth Ermel da Costa Monteiro}

Amiga da professora Fernanda desde a criação do Instituto de Macromoléculas

Conheci a professora Fernanda em 1971, quando fui aceita no Curso de Pós-Graduação em Química Orgânica do Instituto de Quimica da UFRJ. Naquela ocasião ela já fazia parte do Grupo de Polímeros, criado pela professora Eloisa Mano em 1968, tendo acabado de obter o título de

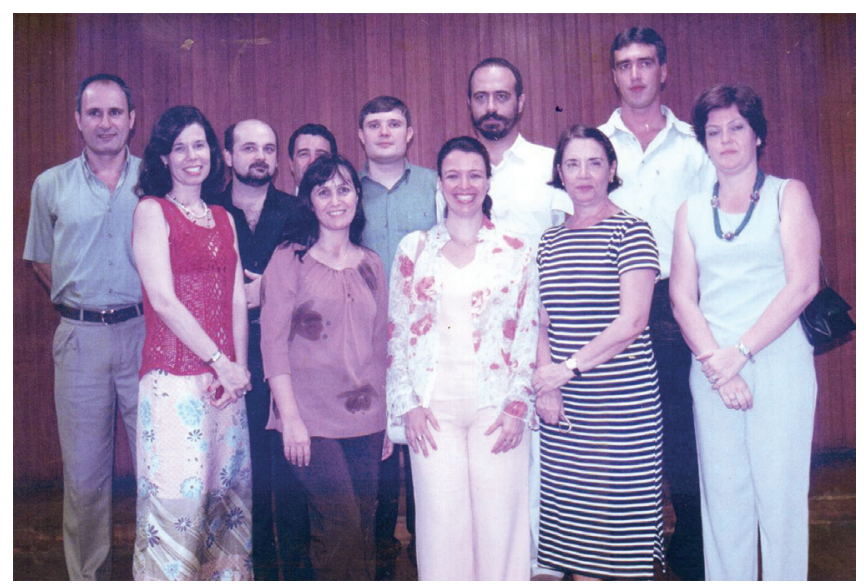


Mestre em Ciências e estava iniciando o doutorado, sob a orientação do Professor Ailton Gomes. Os alunos de Pós-Graduação ainda ocupavam laboratórios que eram da Escola de Química, na Praia Vermelha, que eram amplos, mas devido ao número elevado de alunos tornava o espaço disponível para cada aluno bastante limitado. Além disso, os recursos para aquisição de material $e$ equipamentos de pesquisa eram bastante reduzidos, sendo por vezes até inexistentes. Se por um lado, isto dificultava o desenvolvimento das pesquisas, por outro proporcionou entrosamento e solidariedade entre os estudantes, de tal forma que o grupo tornou-se coeso. Aqueles que apresentavam maior capacidade e conhecimento de auxiliar os demais, tanto no campo científico quanto no individual, se destacavam no grupo e assim surgiu a liderança da professora Fernanda. Desde essa época chegava cedo ao laboratório e permanecia trabalhando até tarde, e ainda dava aulas de Química Orgânica no IQ. Depois de casada e com duas filhas conseguia dividir seu tempo entre as atividades domésticas, docentes e de pesquisa. Depois de obter o título de Doutora em Ciências, em 1981, com a criação do IMA e do Curso de Pós-Graduação em Ciência e Tecnologia de Polímeros, a professora Eloisa Mano convidou-a para Coordenar a Pós-Graduação, cargo que desempenhou até 1998 com eficiência, dedicação e participação destacada no processo de consolidação do curso. Nos últimos anos assumiu o cargo de Professor titular da UERJ, mas manteve o vínculo com o IMA como professora Colaboradora. Entre as características da sua personalidade, destacam-se dedicação à pesquisa, competência, sensibilidade e solidariedade sem deixar de ser exigente. No convívio com seus alunos sempre manteve uma relação que ultrapassava o profissionalismo e produzia vínculos de amizade muitas vezes duradoura. Nos momentos de dificuldade de alunos, funcionários ou colegas, estava sempre disponível para dar apoio e ajudar dentro de suas possibilidades. Por isso, tornou-se uma figura inesquecível seja no âmbito profissional ou pessoal, com sua maneira peculiar de ser forte, sensata, amiga, que estará sempre presente em nossa lembrança.

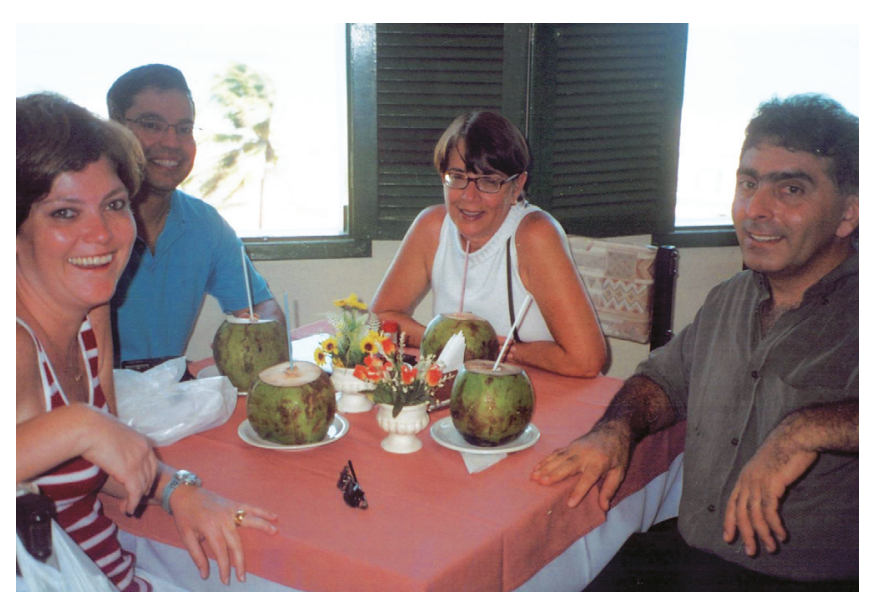

\section{Nota do professor Estêvão Freire}

Ex-aluno da professora Fernanda

Tive maior convivência com a professora Fernanda Coutinho como aluno, tanto nas aulas de graduação na disciplina Química Orgânica III, na UFRJ, quanto nas aulas de Pós-Graduação do IMA. Posso dizer que ela foi uma das melhores professoras que tive, mas o que isso significa? Significa que não sentíamos o tempo passar durante suas aulas, que ela demonstrava domínio dos assuntos abordados e passava aquela vontade de saber mais, de se aprofundar mais. Em suas atividades administrativas era notória a firmeza com que conduzia a Pós-graduação do IMA, buscando elevar sempre o nome dessa instituição. Em suma, sua dedicação, empenho, liderança e compromisso com a Universidade são deixados para nós como exemplo a ser seguido e serão luzes que irão com certeza ajudar a nos guiar em nossas vidas profissionais.

\section{Depoimento da professora Thais Helena Sydenstricker Ex-aluna da professora Fernanda}

A professora Fernanda merece ser homenageada por nós, alunos, ex-alunos, amigos, empregados e familiares. Qualquer que fosse o tipo de relação, sua amizade $e$ generosidade sempre se ressaltavam. Era uma amiga, orientadora, mãe de tantos, conselheira e sempre, por mais que a professora Eloisa dissesse que era impossível ter tudo, trabalho e família, ela sempre colocava a família em primeiro lugar e era excelente profissional. Ela podia tudo porque seu coração era muito grande e, da sua forma, conseguia encontrar tempo, sempre tão precioso.

Ah, quantas lembranças! Como ex-aluna, sempre admirei sua eficiência, rapidez, seu jeito direto e invariavelmente brusco de nos fazer crescer. "É, eu sou a portuguesa e vocês fazem as burrices"! Ou então, obedecer a uma linda regra sua que dizia "Não se critica o chefe"! E eu, respondia, "se pudesse criticar o chefe, diria isso e aquilo mas não posso" e ela ria, satisfeita... E a expectativa de receber os textos de tese, trabalhos, resumos, o que fosse, corrigido já no dia seguinte da entrega, com seu toco de lápis meio sem ponta e que vinham sempre com recados? Uma vez, reclamou da mudança brusca de tema no meio de uma revisão bibliográfica e, então, tomei mais cuidado no texto seguinte: "Caro leitor, está preparado? Vamos mudar de assunto"! Como gostava de brincar com a professora Fernanda!

No final dos anos 80 fui trabalhar com ela no IMA no projeto dos catalisadores Ziegler-Natta. Ela já me conhecia há tempos: eu era a estagiária super tímida da Cristina que andava com os cabelos nos olhos. Então, já minha orientadora, visitava o laboratório todos os dias de manhã, depois do café com professora Elisabeth. Todos nós de Ziegler (e os demais) esperávamos ansiosos a sua visita para perguntar isto e aquilo até que Luiz e eu tivemos uma 
idéia brilhante: preparar uma isca! Ah, funcionou super bem; ela vinha direto tomar nosso café e comer os biscoitos que ficavam na janela do laboratório antes mesmo do café com a professora Elisabeth e sem passar nas "meninas" do laboratório das resinas. Que delicioso tempo aquele das suas rondas matinais! E os pestes? Ariosvaldo, com aquela calma bovina, que escutava as broncas com os olhos enormes arregalados, era o seu preferido. Ah, isso porque ela dizia que era imparcial, imagine!! Dividíamosnos entre pestes, os sensiveis, os muitos trabalhadores e desses, os mais cuidadosos como a Neusa e os rapidinhos, como a própria professora Fernanda que às vezes deixava os detalhes de lado... Uma vez, como não tinha envelope de tamanho normal, mandou uma carta para um editor de revista em um envelope desses de floricultura, que quase não coube o endereço! Estava pronto!!! E como não se criticava o chefe, ela recebia o recado pelo olhar e ria, satisfeita com a própria regra, com seu pequeno império onde reinava feliz, resolvendo nossos problemas, ajudando a todos que podia, incentivando cada um de nós do seu jeito peculiar, dando as merecidas broncas e as que às vezes nos faziam chorar. E então, visto que tinha exagerado, não pedia desculpas diretas, isto nunca, mas de outra forma, compensava o ímpeto do ânimo sobressaltado... A primeira vez que me desfiz em lágrimas foi quando tive a péssima idéia de perguntar em aula se a data da prova de Mecanismos poderia ser mudada. Não estava preparada para a fúria da resposta e as lágrimas corriam indisfarçáveis apesar dos óculos escuros... E ela se preocupava não somente com nossos trabalhos mas também com nossos filhos, maridos, família. Vivia comprando lembrancinhas para as crianças que iam nascendo. O nome do meu filho Fernando foi em sua homenagem. Lembro de ter dito a ela no jardim do IMA que a ultrassonagrafia mostrou que não era uma menina como eu queria e ela foi logo apontando as vantagens de ter 2 filhos homens!

Seu profissionalismo e amor às pessoas transformaram muitas coisas. O bem que levou a tantos alunos e pessoas ao seu redor era uma espécie de talento seu, único, alegre, simpático e sempre muito simples. Quando em 1997 terminei meu doutorado, comprei um cinzeirinho de cristal com dois pássaros foscos bebendo água, achei que

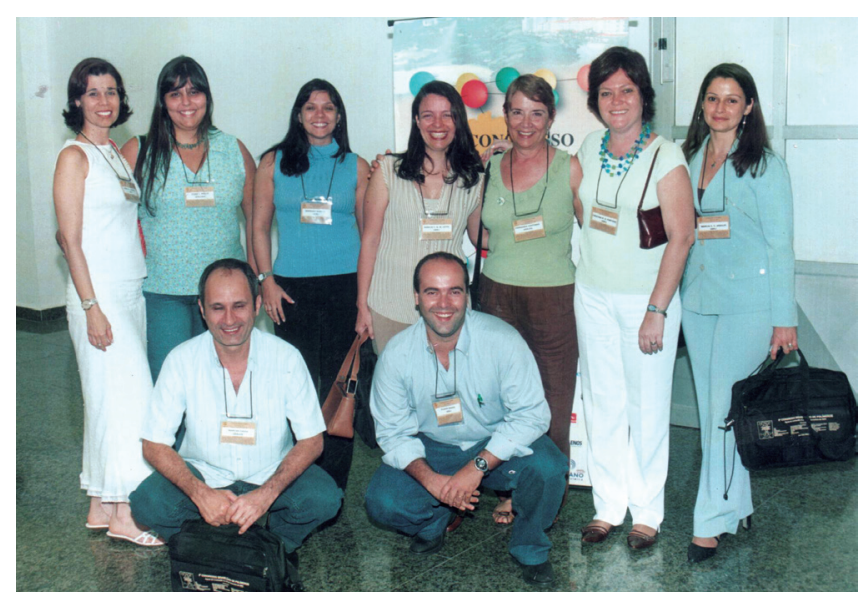

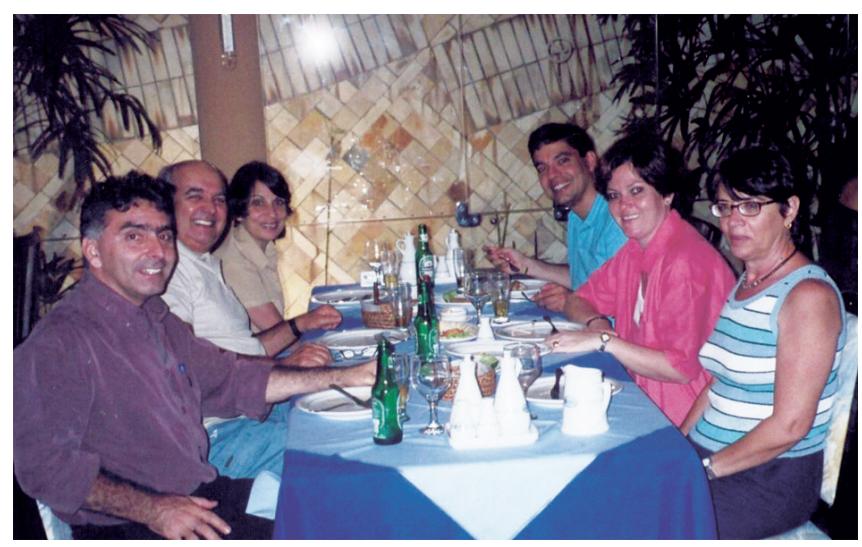

iria gostar, pois adorava seus patos. Escrevi uma poesia para ela, mas não tive coragem de entregar. Agora, mesmo sem coragem, escrevo esse documento, não de despedida, pois ela sempre estará conosco nos pequenos detalhes, nas situações do cotidiano, na nossa vida. É só entrar na $\mathrm{Mr}$ Cat, por exemplo, para lembrar que era uma loja que gostava e onde comprávamos seus presentes de aniversário ou final de ano. Sempre admirei como ela respeitava a forma como seus diferentes alunos escreviam: uns mais objetivos, outros super falantes etc. Achava incrivel ela não fazer os alunos perderem tempo buscando materiais, providenciava tudo com antecedência com sua eficiência de sempre!

Que pena que a professora Fernanda não conheceu pessoalmente meu marido Hector apesar da sua torcida para, finalmente, eu ter encontrado o meu amor. Em julho de 2006, no Macro2006, nos encontramos e ela curtiu muito as histórias românticas que contei durante nosso almoço no shopping. Não consegui fotografar meu gato fazendo xixi no vaso sanitário, mas ela ficou admirada de tal façanha e teria adorado a foto! Não tive a oportunidade de comprar uma grosa de lápis americanos e um apontador mecânico de mesa, desses que funcionam bem, para darlhe de presente. Era um presente que sempre pensei em dar a ela por causa dos seus tocos de lápis que usava nas suas correções. Desconfio, sem certeza, que adorava seus tocos de lápis que BZZZ, BZZZ, BZZZ escreviam rápido e forte! $A$ rápida dona dos lápis sem ponta perderia menos tempo apontando tocos de lápis que te acompanhavam até o final dos seus escritos. Da mesma forma, acompanharemos até o final de nossas vidas essas lembranças bonitas, escrevendo nossas histórias onde professora Fernanda fez parte tão importante.

\section{Nota da professora Elizabete Lucas \\ Ex-aluna da professora Fernanda}

Apesar de hoje estar como Diretora do IMA e ter tido a Fernanda como colega de profissão, o que mais ficou marcado foi a época de nossa relação professor-aluno. Desse tempo, muitas coisas podem ser ditas que foram 
testemunhadas por todos que desfrutaram do convívio com a professora Fernanda, por exemplo, sua destacada habilidade didática. Alguns a criticavam por seu tratamento diferenciado diante dos alunos fora da sala de aula. Diz-se que de alguns ela exigia alta produção e elevado desempenho com autossuficiência, enquanto outros eram por ela "protegidos", pois parte do trabalho ela mesma fazia e o desempenho mediano ou, às vezes até mesmo, um pouco abaixo da média não sofria todas as críticas esperadas por parte de uma profissional com seu nível de capacidade pessoal e de exigência para com os alunos. Neste depoimento, depois de longo convívio com a Fernanda e com a experiência que a academia me trouxe, posso assegurar que o tratamento diferenciado realmente existia. Entretanto, não tinha como base preferências pessoais ou aleatórias, mas sim um trabalho de estímulo ao crescimento profissional e pessoal diferenciado, de modo que cada um pudesse ir até onde fosse capaz. Como as pessoas são muito diferentes em suas formações acadêmicas, personalidades e talentos naturais, não parece mesmo correto utilizar de estímulos padronizados para a formação profissional de um indivíduo. Esse comportamento nos permite observar que sua contribuição foi significativa para TODOS aqueles que se permitiram receber suas orientações e sugestões profissionais, de certo modo, personalizadas. Apesar de não ter tido a Fernanda como orientadora de Tese, em seu papel de coordenadora de pós-graduação, acompanhava a trajetória de cada aluno do Programa de Pós-Graduação em Ciência e Tecnologia de Polímeros. Por isso, tive a oportunidade de receber sugestões valiosas para meu crescimento profissional.

Por sua elevada capacidade como professora, pesquisadora, orientadora científica e acadêmica e talento para a formação de profissionais, em um sentido mais amplo do que meramente de transmitir conhecimento científico e tecnológico, resumo meu sentimento por essa pessoa especial em ADMIRAÇÃO.

\section{Depoimento da professora Cristina Russi \\ Ex-aluna da professora Fernanda}

Conheci Fernanda Coutinho como professora de Química Orgânica e logo me encantei com ela. Surgiu a oportunidade e fui sua aluna de Iniciação Científica. As reações que eu fazia duravam 8 horas e Fernanda me dava carona às 5 h30 das manhãs de sexta-feira para que eu pudesse montar os experimentos antes da minha aula começar. Fernanda chegava no IMA/UFRJ às 6 h da manhã. Após 5 anos de IC, fiz Mestrado com ela. Nossa amizade já era tão grande que a convidei para ser madrinha do meu casamento. Após 7 anos de trabalho na área de síntese de polímeros, decidi mudar de projeto e foi a própria Fernanda quem me indicou para trabalhar em um projeto na área de tecnologia de Polímeros no meu doutorado, no qual ela não seria mais minha orientadora. Mesmo assim, foi Fernanda quem mais uma vez indicou um professor para me orientar na França durante o meu doutorado sanduíche. Foi ela também quem me ajudou no pedido de prorrogação dessa estadia, já que fui inicialmente para um período de 6 meses e acabei ficando 1 ano. Fernanda também me ajudou bastante nas horas difíceis de solidão na França, com suas palavras de incentivo para que eu não voltasse para o Brasil antes do término do trabalho. Fernanda fez parte da banca do meu Doutorado e alguns anos depois passamos a ser colegas de trabalho no Departamento de Processos Químicos do Instituto de Química da Universidade do Estado do Rio de Janeiro, onde ela foi responsável pela criação do Curso de Pós-graduação em Química do qual faço parte. Fernanda continuou a me ajudar, sob sua coordenação montamos um projeto para o CNPq para a aquisição dos primeiros equipamentos do Laboratório de Processamento de Polímeros do IQ/UERJ, que passará a se chamar Laboratório de Processamento de Polímeros professora Fernanda Coutinho. Espero que esse depoimento possa mostrar um pouco quem era nossa amiga FERNANDA MARGARIDA BARBOSA COUTINHO e lamento realmente pelos alunos que não tiveram a oportunidade de conhecê-la e trabalhar com ela.

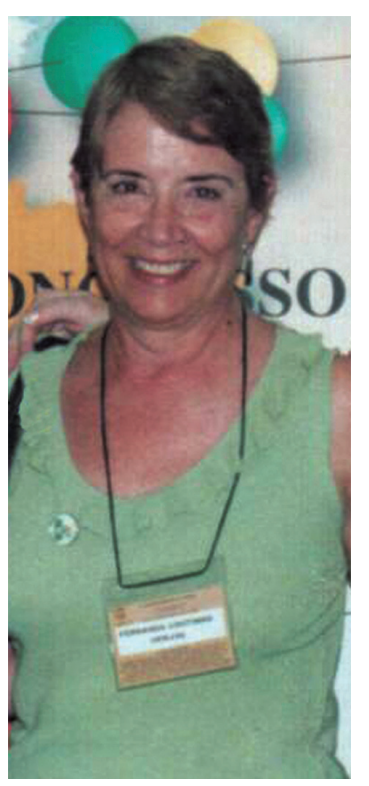




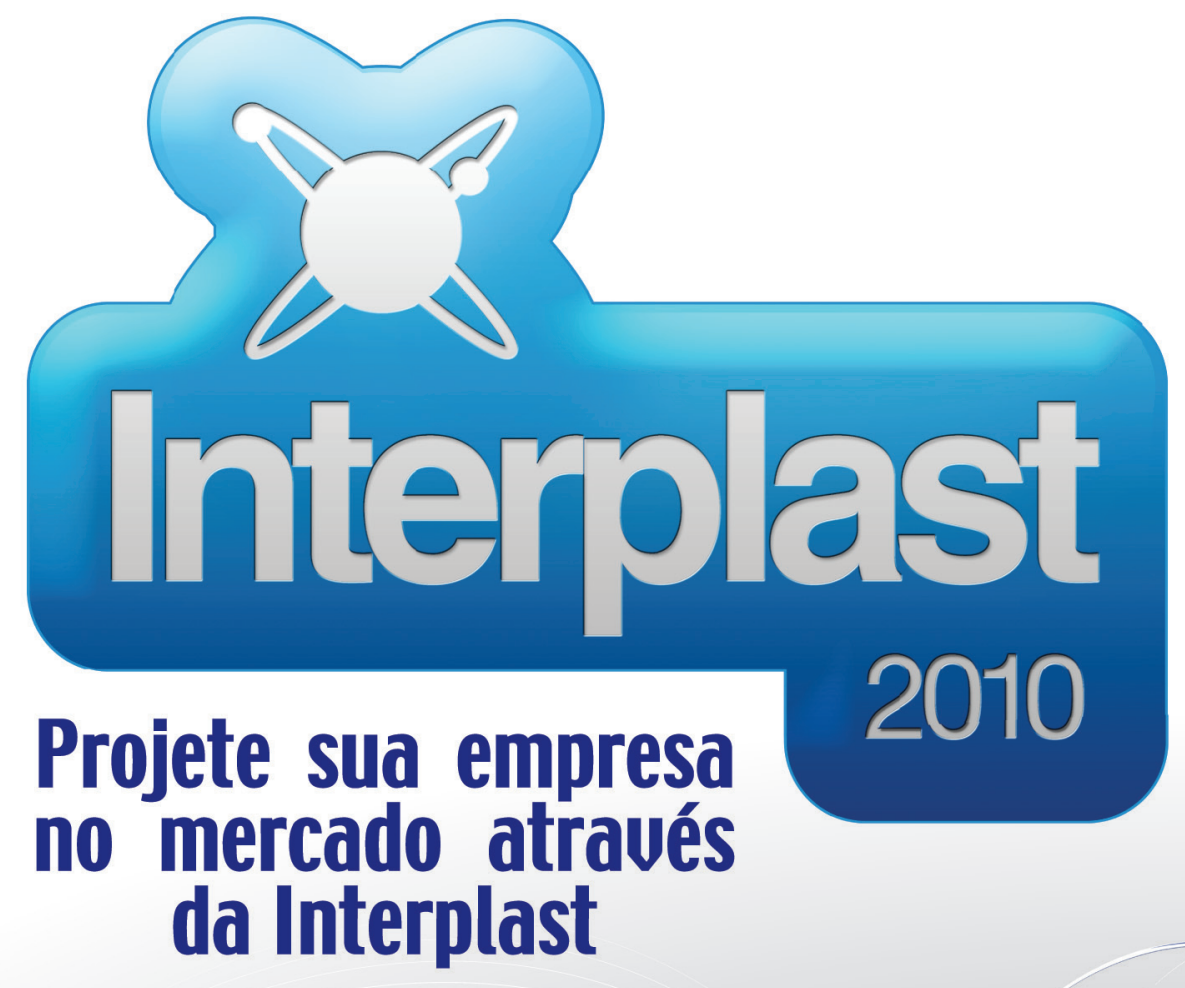

Promoção e Realização:

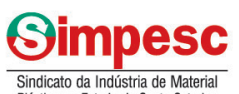

Sindicato da Indústria de Material

Apoio Oficial:

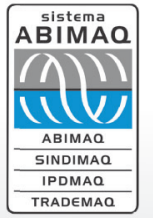

Com 0 atual panorama da economia mundial, empresas que mantinham fornecedores usuais mostram-se receptivas a novas alternativas de parceria. E as reestruturações internas que vêm ocorrendo em muitas delas reforçam essa tendência.

A $6^{a}$ edição da Interplast reúne ampla gama de empresas das mais diversas áreas de interesse do setor plástico, provenientes de vários Estados do Brasil e de outros países, favorecendo as oportunidades de fechamento de negócios.

Independentemente do tamanho da sua empresa ou do local onde está estabelecida, esta é a melhor forma para fazer excelentes contatos, promover sua marca e vender mais.

\section{A Interplast 2010 é a sua chance para aparecer no mercado e negociar com quem decide:}

É a maior feira do Sul do Brasil, segundo maior mercado do setor de plásticos da América Latina.

Tem baixo valor de investimento, mas grande potencial de geração de negócios, e a cada edição supera as expectativas dos expositores.

Feira e Congresso Macional de Integração da Tecnologia do Plástico

De 23 a 27 de figosto, no megaCentro Expoville em Joinuille - SC
Reserve já o seu espaço e garanta participação neste promissor mercado: www.interplast.com.br

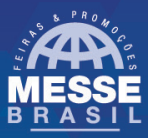

Fone: (47) 34513000 wWw. messebrasil.com.br feiras@messebrasil.com.br 